\title{
Clinicopathological characteristics of young versus older patients with breast cancer
}

\author{
A retrospective comparative study from the Madinah region of Saudi \\ Arabia
}

Abdulkader M. Albasri, MBBCh, PhD.

\begin{abstract}
الأهداف : تحليل السمات الإكلينيكية المرضية لمرضى سرطان الثدي الشابات

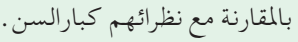

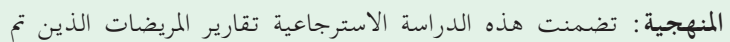

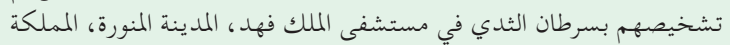

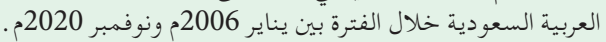

النتائج: خلال فترة الدراسة، تم تشخيص 708 مريضة بسرطان الثدي.

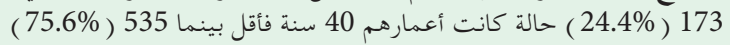

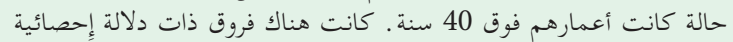

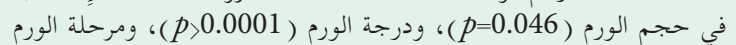

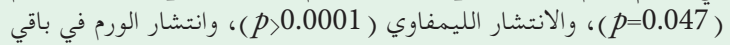

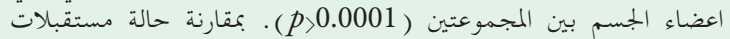

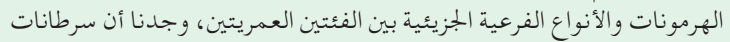

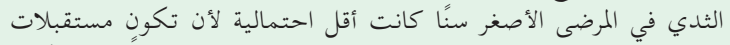

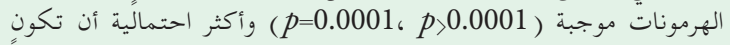

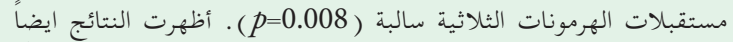
زيادة سرطانات الثدي من النوع HER2/neu في المرضى الأصغر سنًا . $(p=0.016)$

الحخلاصة : علِى الرغم من أن سرطان الثدي لدى الشابات غير شائع، إِلا أنه قد

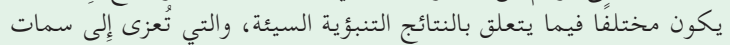

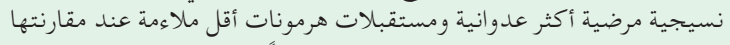
بالحالات التي تم تشخيصها عند النساء الأكبر سنًا.
\end{abstract}

Objectives: To compare the clinicopathological, histological and immunohistochemical features of breast cancer $(\mathrm{BC})$ in between young ( $\leq 40$ years) and older ( $>40$ years) patients.

Methods: This retrospective study included histopathological reports of all patients with primary BC diagnose at the King Fahad Hospital, Madinah, Saudi Arabia between January 2006 and November 2020.
Results: During the study period, a total of 708 patients with BC were identified; 173 cases $(24.4 \%)$ were $\leq 40$ years old and $535(75.6 \%)$ were above 40 years. There were significant differences in tumor size $(p=0.046)$, tumor grade $(p<0.0001)$, tumor stage $(p=0.047)$, lymphovascular invasion $(p<0.0001)$, and distant metastasis $(p<0.0001)$ between the 2 groups. Comparing the status of the hormone receptors and molecular subtypes between the 2 age groups, BCs in the younger patients were triple-negative $(p=0.008)$ in majority of the cases and less likely to be estrogen receptor (ER) and progesterone receptor (PR) hormone receptors-positive $(p=0.0001, p<0.0001)$. Young patients exhibited the HER2/neu type with more frequent statistical significance $(p=0.016)$ and the tumor type luminal A ( $p=0.002)$ with less frequent statistical significance compared to old patients.

Conclusion: Although BC in young women is uncommon, it may be different with regards to poor prognostic outcomes, which are attributed to more aggressive histopathological features and less favorable receptor status when compared to the cases diagnosed in older women.

Keywords: breast cancer, Madinah, Saudi Arabia

Saudi Med J 2021; Vol. 42 (7): 769-775

doi: 10.15537/smj.2021.42.7.20200750

From the Department of Pathology, Taibah University, Al-Madinah Al-Munawwarah, Kingdom of Saudi Arabia.

Received 25th November 2020. Accepted 30th May 2021.

Address correspondence and reprint request to: Dr. Abdulkader $M$. Albasri, Department of Pathology, Faculty of Medicine, Taibah University, Al-Madinah Al-Munawwarah, Kingdom of Saudi Arabia. E-mail:abdbasri@hotmail.com

ORCID ID: http://orcid.org/0000-0002-1824-4025 
T he breast cancer (BC) is the most common cancer throughout the world and the fifth common cause of cancer death. ${ }^{1}$ In year 2020, GLOBOCAN in their statistics reported 2.26 million cases of $\mathrm{BC}$ which accounted for $11.7 \%$ of all cancer cases throughout the world. ${ }^{2}$ However, a recent Saudi Cancer Registry (SCR) reported 2,282 new cases of BC in the whole Saudi Arabia accounting for $17.3 \%$ of all cancer cases, which was significantly higher than the GLOBOCAN statistics, moreover, BC was found to be $30.4 \%$ of all new cancer diagnosed in women making it the most common cancer in the kingdom. ${ }^{3}$ While, in the western population the $\mathrm{BC}$ in the women less than 40 years of age is uncommon and accounts for $3.7 \%-6.6 \%$ of the total number of $\mathrm{BC}$ cases..$^{4-7}$ However, a very high rate of $\mathrm{BC}$ in the young patients (29\%-31.6\%) was reported in the literature from Nigeria and India. ${ }^{8,9}$ In Saudi Arabia also the figures are higher than the western countries, according to the latest SCR report, $18.9 \%$ of all BC cases are diagnosed in women $<40$ years old. ${ }^{3}$

Compared to older patients, BC diagnosed at a young age is likely to behave more aggressively and prone to present with a high grade tumor, larger tumor size, more lymph node involvement, lymphovascular invasion and an advanced tumor stage with more triplenegative, human epidermal growth factor receptor 2 (HER2/neu) overexpression and fewer luminal A and $\mathrm{B}$ breast cancer. ${ }^{10-13}$ In line with this, higher incidence of loco-regional recurrences and distant metastases have been reported in younger BC patients, contributing to a poorer prognosis. ${ }^{14}$ Accordingly, different treatment strategies are required to treat this patient population in order to achieve optimal therapeutic outcomes. The major issues in managing the $\mathrm{BC}$ in young patients requires a multidisciplinary team involving many specialties including psychological approach, preservation of the fertility, management of future pregnancies and financial implication on the individual and the family. Keeping in mind the high incidence rate of BC in Saudi women, the principle aim of this retrospective study was to report and analyze the clinicopathological, histological and immunohistochemical features of $\mathrm{BC}$ between the young and old female patients from Madinah, Saudi Arabia.

Disclosure. Authors have no conflict of interests, and the work was not supported or funded by any drug company.
Methods. This study was conducted retrospectively to analyze BC cases from January 2006 to November 2020 at King Fahad Hospital (KFH) Madinah, Saudi Arabia. During this period, a total of 708 cases of $\mathrm{BC}$ were reported in the histopathology laboratory of the KFH. Patients' demographic informations such as age, gender, nationality and final diagnosis of the biopsy or surgery of the breast tumor, tumor type, tumor grade, tumor size, status of lymph nodes, lymphovascular invasion, any available history of recurrence, type of surgery (namely, breast conserving surgery or modified radical mastectomy), and status of hormone receptors were retrieved from the histopathology laboratory computer database. The inclusion criteria were the diagnosis of primary BC (both invasive as well as in-situ) in Saudi female patients of all age groups. Non-Saudis, male patients and metastatic BCs were excluded from the study. The 2019 World Health Organization (WHO) classification of $\mathrm{BC}$ was applied for histological typing. ${ }^{15}$ The Modified Bloom-Richardson (MBR) system was used to assess the tumor grade, while the estrogen and progesterone receptor (ER, PR) reactivity was evaluated according to the St Gallen Consensus 2009 which was documented by a positive nuclear staining pattern. ${ }^{16}$ The Her-2/neu staining was assumed positively reacting when a strong complete membranous staining was noted in more than $10 \%$ of tumor cells. Based on the receptor status of $\mathrm{BC}$ in our cohort we classified them according to Dai et $\mathrm{al}^{17}$ molecular subtypes:

$\mathrm{ER}+, \mathrm{PR}+/-$, Her-2/neu Negative - Luminal A (ER + and low grade)

$\mathrm{ER}+, \mathrm{PR}+/-$, Her-2/neu + - Luminal B (ER + but often high grade)

ER -, PR -, Her-2/neu + - Her-2/neu Amplified

ER -, PR -, Her-2/neu Negative - Basal like (Triple negative breast cancer)

The nuclear immunostaining of Ki67 was assessed by counting at least 500 tumor cells per case across 5 high power fields of the section under microscope. The Ki67 proliferative index (PI) was scored as high when $>25 \%$ of the tumor cells were positive; and low when $<25 \%$ of the tumor cells were positive.

The patients were assigned in 2 groups; Group 1 comprises a total of 173 patients equal to or less than 40 years of age (young patients), and Group 2 which comprises 535 patients more than 40 years of age (old patients). The American Joint Committee on Cancer 
(AJCC seventh edition) tumor (T), nodes $(\mathrm{N})$, and metastases (M) (TNM) staging system for BC was used to stage the patient in both the groups in our cohort.

Both the groups were compared for clinicopathological, histological and immunohistochemical features. Statistical analysis of our data was performed with Statistical Package for Social Sciences (SPSS), version 21.0 (IBM Corp. Armonk, New York, USA). Comparisons of categorical variables between the 2 groups were assessed using Pearson's Chi-square test. In all statistical tests, a $p<0.05$ was considered statistically significant. Approval for the publication of this study was taken from the Department of Pathology, KFH, Madinah Saudi Arabia.

Results. An aggregate of 708 women with BC were included in this study; 173 cases $(24.4 \%)$ were $\leq 40$ years old (Group 1) and 535 (75.6\%) were above 40 years (Group 2). The age for all the patients ranged between 20 and 112 years with a mean age of 50.6 years. The mean age of the younger group was 34.1 years (range 20-40 years) and the mean age of the older group was 55.9 years (range $41-112$ years).

Our findings of clinicopathological, histological, and immunohistochemical features and their comparison between Group 1 and Group 2 is summarized in Table 1. Significant statistical differences were noted of the following parameters between the 2 groups; tumor size ( $4.5 \mathrm{~cm}$ in Group 1 and $3.7 \mathrm{~cm}$ in Group 2, $p=0.046$ ), tumor grade (more patients with grade III tumors in Group 1), lymphovascular invasion (28.5\% of patients in Group 1, $p<0.0001)$, distant metastasis and stage IV disease (more in Group 1, $p<0.0001$ and $p=0.046$ ). The invasive ductal carcinoma (IDC) was the most common histological subtypes of breast cancer reported in both groups. Moreover, other histological subtypes and ductal carcinoma in situ (DCIS) showed no significant statistical difference. However, a significant difference was noted in the occurrence of invasive lobular carcinoma (ILC), which was seen more frequently in Group 2 patients $(p=0.028)$ as shown in Figure 1.

The other findings such as lymph node status $(p=0.606)$, type of surgery $(p=0.150), \operatorname{Ki} 67 \mathrm{PI}(p=0.082)$, locoregional recurrence $(p=0.163)$, and concomitant DCIS $(p=0.441)$ did not significantly differ between the 2 age groups.

Comparing the status of the hormone receptors and molecular subtypes between the 2 age groups, we found that the younger patients in Group 1 who tended to present with $\mathrm{BC}$ were less likely to be estrogen receptor (ER) and progesterone receptor $(\mathrm{PR})$ hormone
Table 1 - Comparison of clinicopathological features between the young and old patients ( $\leq 40$ years and $>40$ years of age) at diagnosis.

\begin{tabular}{|c|c|c|c|}
\hline Variables & $\begin{array}{l}\text { Group } 1 \\
(\leq 40 \text { years }) \\
\text { n }(\%)\end{array}$ & $\begin{array}{c}\text { Group } 2 \\
(>40 \text { years) } \\
\text { n }(\%)\end{array}$ & $P$-value \\
\hline \multicolumn{3}{|l|}{ Tumor type } & \multirow{6}{*}{0.174} \\
\hline Invasive ductal & $153(88.5)$ & $458(85.6)$ & \\
\hline Invasive lobular & $2(1.1)$ & $33(6.2)$ & \\
\hline $\begin{array}{l}\text { Ductal carcinoma } \\
\text { in situ }\end{array}$ & $13(7.5)$ & $27(5)$ & \\
\hline $\begin{array}{l}\text { Lobular carcinoma } \\
\text { in situ }\end{array}$ & - & $2(0.4)$ & \\
\hline Other & $5(2.9)$ & $15(2.8)$ & \\
\hline \multicolumn{3}{|l|}{ Tumor size } & \multirow{4}{*}{0.046} \\
\hline$\leq 2 \mathrm{~cm}$ & $23(16.2)$ & 85 (26.6) & \\
\hline$>2 \mathrm{~cm}-\leq 5 \mathrm{~cm}$ & $80(56.3)$ & $162(50.8)$ & \\
\hline$>5 \mathrm{~cm}$ & $39(27.5)$ & $72(22.6)$ & \\
\hline \multicolumn{3}{|l|}{ Histological grading } & \multirow[t]{4}{*}{$<0.0001$} \\
\hline Grade I & $13(8.6)$ & $51(11.2)$ & \\
\hline Grade II & $55(36.2)$ & $242(53.5)$ & \\
\hline Grade III & $84(55.2)$ & $160(35.3)$ & \\
\hline \multicolumn{3}{|l|}{ TNM staging } & \multirow[t]{5}{*}{0.047} \\
\hline Stage 0 & $13(7.7)$ & $27(7.2)$ & \\
\hline Stage I & $58(34.3)$ & $166(44.4)$ & \\
\hline Stage II & 45 (26.6) & $102(27.3)$ & \\
\hline Stage III & $53(31.4)$ & $79(21.1)$ & \\
\hline \multicolumn{3}{|c|}{ Axillary lymph node metastasis } & \multirow[t]{3}{*}{0.606} \\
\hline No & $81(60.9)$ & $183(58.3)$ & \\
\hline Yes & $52(39.1)$ & $131(41.7)$ & \\
\hline \multicolumn{3}{|c|}{ Number of axillary lymph node metastasis } & \multirow[t]{5}{*}{0.129} \\
\hline 0 & $81(60.9)$ & $183(58.3)$ & \\
\hline $1-3$ & $14(10.5)$ & $45(14.4)$ & \\
\hline $4-9$ & $25(18.8)$ & $39(12.4)$ & \\
\hline$\geq 10$ & $13(9.8)$ & $47(14.9)$ & \\
\hline \multicolumn{3}{|c|}{ Lymphovascular invasion } & \multirow[t]{3}{*}{$<0.0001$} \\
\hline No & $49(32.5)$ & $254(62.6)$ & \\
\hline Yes & $102(67.5)$ & $152(37.4)$ & \\
\hline \multicolumn{3}{|l|}{ Distant metastases } & \multirow[t]{3}{*}{$<0.0001$} \\
\hline No & $51(35.7)$ & $285(68.2)$ & \\
\hline Yes & $92(64.3)$ & $133(31.8)$ & \\
\hline \multicolumn{3}{|l|}{ Locoregional recurrence } & 0.163 \\
\hline No & $73(66.4)$ & $159(58.7)$ & \\
\hline Yes & 37 (33.6) & $112(41.3)$ & \\
\hline Type of surgery & & & 0.150 \\
\hline $\begin{array}{l}\text { Breast conserving } \\
\text { surgery }\end{array}$ & $19(66.4)$ & $88(58.7)$ & \\
\hline Mastectomy & $117(33.6)$ & $366(41.3)$ & \\
\hline Estrogen receptor $(E R)$ & & & 0.0001 \\
\hline Negative & $74(51.7)$ & $145(34.1)$ & \\
\hline Positive & $69(48.3)$ & $280(65.9)$ & \\
\hline Progesterone receptor & status & & $<0.0001$ \\
\hline Negative & $87(56.9)$ & $148(32.9)$ & \\
\hline Positive & $66(43.1)$ & $301(67.1)$ & \\
\hline Her2neu status & & & 0.002 \\
\hline Negative & $84(55.3)$ & $294(69)$ & \\
\hline Positive & $68(44.7)$ & $132(31)$ & \\
\hline Tumor subtype & & & $<0.0001$ \\
\hline Luminal A & $32(21.5)$ & $163(43.1)$ & \\
\hline Luminal B & $28(18.8)$ & $75(19.8)$ & \\
\hline Triple negative & $41(27.5)$ & $50(13.2)$ & \\
\hline HER2-postive & $48(32.2)$ & $90(23.8)$ & \\
\hline In situ component & & & 0.441 \\
\hline Negative & $87(61.7)$ & $163(57.8)$ & \\
\hline Positive & $54(38.3)$ & $119(42.2)$ & \\
\hline Ki67 expression & & & 0.082 \\
\hline Negative & $71(53.4)$ & $219(62)$ & \\
\hline Positive & $62(46.6)$ & $134(38)$ & \\
\hline
\end{tabular}


receptors-positive $(p=0.0001, p<0.0001)$ and more likely to be triple-negative $(p=0.008)$. While the old patients in Group 2 were more likely to be ER and PR receptor positive and Her-2/neu negative (luminal A type, $p=0.002$ ). Young patients in Group 1 were more in Her-2/neu amplified category $(p=0.016)$. We further analyzed the ER positive and ER negative tumors in

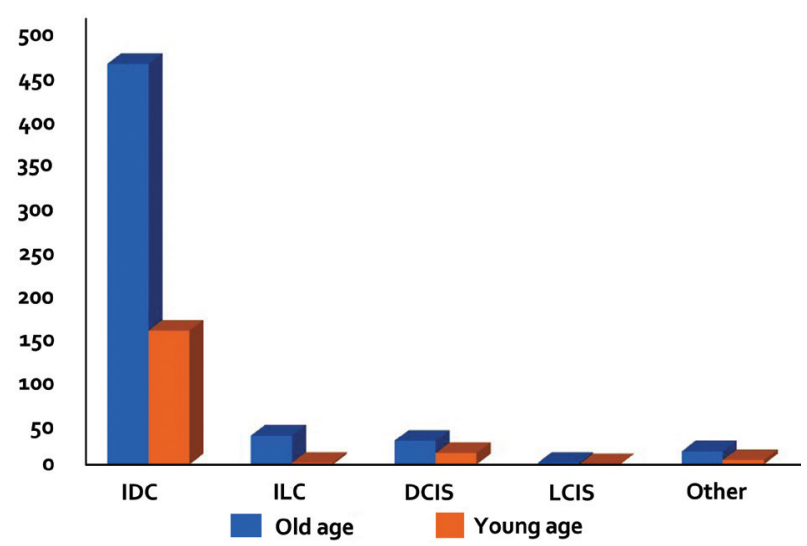

Figure 1 - The differences in histological subtypes between the younger and older patients ( $p=0.174)$. IDC: invasive ductal carcinoma, ILC: invasive lobular carcinoma, DCIS: ductal carcinoma in situ, LCIS: lobular carcinoma in situ

Table 2 - Sub analysis of estrogen receptor (ER) positive tumors with respect to age, tumor size, tumor grade, lymphovascular invasion, lymph node metastasis, distant metastasis and Ki67 expression.

\begin{tabular}{lccc}
\hline Variables & $\begin{array}{c}\leq 40 \text { with } \\
\text { ER+ve (n=69) }\end{array}$ & $\begin{array}{c}>40 \text { with } \\
\text { ER+ve }(\mathbf{n}=280)\end{array}$ & $P$-value \\
\hline $\begin{array}{l}\text { Tumor size } \\
\leq 2 \mathrm{~cm}\end{array}$ & $10(14.5)$ & $57(20.4)$ & 0.473 \\
$>2 \mathrm{~cm}-\leq 5 \mathrm{~cm}$ & $47(68.1)$ & $184(65.7)$ & \\
$>5 \mathrm{~cm}$ & $12(17.4)$ & $39(13.9)$ & \\
Histological grading & & & 0.0001 \\
Grade I & $4(5.8)$ & $25(8.9)$ & \\
Grade II & $32(46.4)$ & $192(68.6)$ & \\
Grade III & $33(47.8)$ & $63(22.5)$ & \\
Axillary lymph node metastasis & & \\
No & $17(24.6)$ & $187(66.8)$ & \\
Yes & $52(75.4)$ & $93(33.2)$ & \\
Lymphovascular invasion & & & \\
No & $11(15.9)$ & $96(34.3)$ & \\
Yes & $58(84.1)$ & $184(65.7)$ & \\
Distant metastases & & & \\
No & $13(52.0)$ & $113(57.3)$ & \\
Yes & $56(48.0)$ & $167(42.7)$ & \\
Ki67 expression & & & \\
Negative & $34(49.3)$ & $124(44.3)$ & \\
Positive & $35(50.7)$ & $156(55.7)$ & \\
\hline \multicolumn{4}{r}{ Values are expressed as number and percentage (\%) } \\
\hline
\end{tabular}

both young and old age groups of our cohort with respect to tumor size, tumor grade, lymphovascular invasion, lymph node metastasis, distant metastasis and Ki67 expression. A significant correlation between the ER positive tumors in young patient with high grade tumors $(p=0.0001)$, lymphovascular invasion $(p=0.003)$, axillary lymph node metastasis $(p<0.0001)$, and distant metastasis was observed $(p=0.0008)$. The Ki67 expression in ER positive tumors did not show any significance correlation $(p=0.455)$ (Table 2$)$. While ER negative tumors showed a significance correlation with high Ki67 expression $(p<0.0001)$; however, it did not correlate well with other prognostic markers (Table 3).

Discussion. In the current study, young patients ( $\leq 40$ years) accounted for $24.4 \%$ of the total BC cases, which is comparable to other Asian countries, such as China, ${ }^{18}$ South Korea, ${ }^{19}$ Iran, ${ }^{20}$ Pakistan, ${ }^{21}$ and the United Arab Emirates (UAE). ${ }^{22}$ However, it is significantly higher than the $3.7 \%-6.6 \%$ reported in many Western countries. ${ }^{4-7}$

The higher rate of $\mathrm{BC}$ in young patients in our cohort is comparable with the previous data from Saudi women reported by Nuzhat et $\mathrm{al}^{23}$ and Elkum et $\mathrm{al}^{24}$

Table 3 - Sub analysis of estrogen receptor (ER) negative tumors with respect to age, tumor size, tumor grade, lymphovascular invasion, lymph node metastasis, distant metastasis and Ki67 expression.

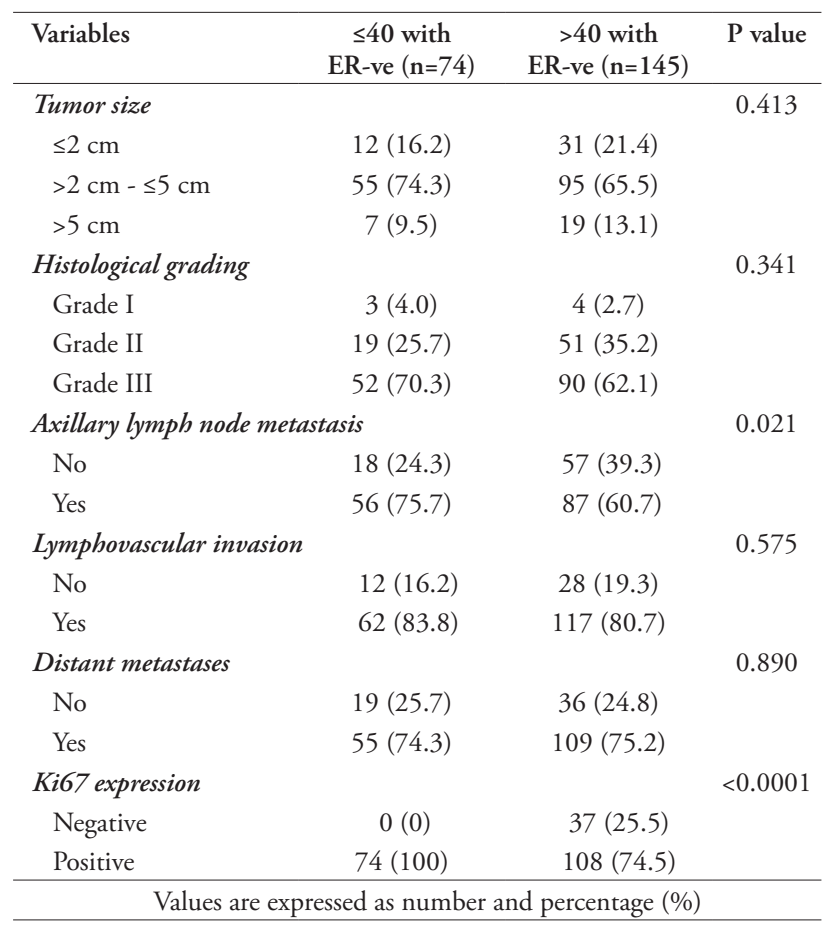


from Riyadh also observed a higher rate of BC (25.2\%$33.2 \%$ ) in young women in Saudi Arabia than the women from the western countries (3.7\%-6.6\%).

Several studies have shown that in developing countries, BC patients are diagnosed a decade earlier than their Western counterparts. ${ }^{25-27}$ This could be attributed to several factors, such as differences in race/ethnic backgrounds, genetic susceptibilities, social background factors, dietary habits and lifestyles, environmental factors, and economic development levels between young women in developing countries and their counterparts in developed countries. However, data in this realm are lacking. Moreover, the young age pyramid could be an additional factor that explains the higher frequency of early onset $\mathrm{BC}$ in the developing countries compared to developed countries. According to the data available from the Saudi General Authority for Statistics, women under 40 years of age represent $74.6 \%$ of the total female population in Saudi Arabia. ${ }^{28}$ This is about 1.5 times higher than that of the USA for the same age group (74.6\% versus $51.2 \%)$, indicating a relative over-population in the young age group in Saudi Arabia, and thus an increase in the incidence of BC in young Saudi women compared to their American counterparts. ${ }^{29}$

Histopathological analysis showed that both the young and elderly groups were dominated by IDC without any significant statistical difference in its proportion. We did not find any significance difference in the DCIS and other subtypes of IDCs between the 2 groups, similar observations were noted by Foo et $\mathrm{al}^{10}$ from Singapore and Telfah et $\mathrm{al}^{11}$ from Jordan. Interestingly, our patients in Group 2 showed statistically significant number of ILC, a similar finding was observed by the various previous authors. ${ }^{10-12}$

In this study, we observed that the young women with $\mathrm{BC}$ reported with an adverse clinicopathological characteristics, including larger tumor size, higher grade, advance tumor stage, more lymphovascular invasion, and more distant metastases compared with older women. Similar to our data, the study conducted by Foo et $\mathrm{al}^{10}$ of 843 women with BC from Singapore showed that young patients had a higher tumor grade and vascular invasion compared with older women $(p=0.012$ and $p=0.034) .{ }^{10}$ Telfah et $\mathrm{a}^{11}$ from Jordan also reported similar results and found that young BC patients had larger tumors $(p=0.02)$, increased lymphovascular invasion $(p=0.05)$, and higher tumor grade $(p=0.0001)$ compared with the disease arising in older patients. In addition, Maggard et $\mathrm{al}^{12}$ from the USA found that young patients were more likely to present with more advanced tumor grades and tumor stages than their older counterparts $(p<0.0001$ and $p<0.0001)$. Similarly, Bharat et $\mathrm{al}^{13}$ from the USA reported that the young patients with $\mathrm{BC}$ in their cohort presented at an advance tumor stage with a higher grade and more lymphovascular invasion compared with aged patients ( $p<0.05, p<0.01$ and $p<0.05$ respectively).

In our study, ER and $\mathrm{PR}$ receptor were negative and Her-2/neu overexpression was noted in majority of the young patients. Similar observations of ER and PR negative tumors in young $\mathrm{BC}$ patients were made by Bharat et $\mathrm{al}^{13}$ from the USA. In line with this, Anders et $\mathrm{al}^{30}$ analyzed the microarray data from $784 \mathrm{BC}$ patients, and found that young patients had lower ER and PR mRNA expression, as well as higher HER2/neu expression compared with aged patients. Similarly, Zhang et $\mathrm{a}^{31}$ compared the clinicopathological features of 6,668 cases of young and 143,920 cases of older BC patients, and noticed low prevalence of ER/PR positivity and overexpression of the HER2/neu receptor in young patients compared with older patients. Telfah et al ${ }^{11}$ also reported similar findings in their study and noticed low prevalence of ER positivity and overexpression of the HER2/neu receptor in young patients compared with aged ones. In another detail study on gene profiling of breast cancer in 3,522 women by Azim et al, ${ }^{32}$ from Brussel, Belgium where they subclassified their patients in 3 molecular subtypes (ER+/HER2-, HER2+ and ER-/HER2-) and found that young women had a higher percentage of ER-/HER2- cancers $(p<0.001)$. They also found that young women with $\mathrm{BC}$ have a unique molecular processes, and cancers in them are augmented with extracellular signal regulated kinases and $\mathrm{P} 13 \mathrm{~K}$ signaling genes. They also found that BRCA1 germline mutated breast cancers were significantly associated with younger women. Further sub-analysis of ER receptor status of our cohort showed a significant correlation between the ER negative status with young age $(p=0.0001)$, larger tumor size $(p<0.0001)$, high grade tumor $(p<0.0001)$, and high Ki67 expression $(p<0.0001)$. A similar observation of high Ki67 expression by immunohistochemistry and mRNA expression in young patients by Aine et $\mathrm{al}^{33}$ from Lund University, Sweden.

Currently, it is widely accepted that molecular subtyping of $\mathrm{BC}$ is considered an important prognostic factor, which influences disease prognosis and the patient's outcome. The triple negative breast cancers (TNBC) and the BCs with over expression of Her-2/neu behave more aggressively and have a poor prognosis due to the high risk of lymphnode and distant metastasis and recurrence rate, similar observations were made by $\mathrm{Ma}$ et $\mathrm{al}^{34}$ from Shanghai, China and Al-thobaity ${ }^{35}$ from 
Jeddah, Saudi Arabia. Similarly, Radosa et $a^{36}$ from Memorial Sloan-Kettering Cancer Center, New York also reported that young patients with TNBC presented with larger tumor size and higher tumor stages. Our findings of significantly high rates of triple negative $\mathrm{BC}$ in young women as compared to their older counterparts are in accordance with the previous published research.

Study limitations. The potential limitations of our study are mainly related with the retrospective nature of the study and sample selection from a single tertiary care hospital which might limit the representation of our findings to the general population of the region. Lack of patients' survival data, physicians' choice of therapy (breast conservative surgery, mastectomy, radiation, chemotherapy), BRCA gene profiling, family history and recurrence rate, these limitations are mainly attributed to the sample collection from the histopathology laboratory and limited access to the medical record section of the hospital. Another possible limitation is lack of intrinsic subtyping of $\mathrm{BC}$ in our cohort which might hinder the prognostic and predictive information. Additionally, the lack of comparative sub analysis based on age and ER status is another possible limitation due to the small numbers of cases in our group.

In conclusion, although $\mathrm{BC}$ in young women is uncommon, it may be different with regards to poor prognostic outcomes which is particularly ascribed to more aggressive histopathological features such as higher tumor grade and lymphovascular invasion and less conducive hormonal receptor status when compared to the cases diagnosed in older women. Healthcare professionals should keep the aggressive nature of $\mathrm{BC}$ in young patients in their mind while dealing with the breast abnormalities in this age group. We believe that our study provides a baseline tool for future populationtargeted studies to analyze the behavior of BC in young patients for developing efficient adjuvant therapies for a better outcome in this population.

Acknowledgment. We acknowledge Scribendi (https//www.scribendi.com), the Editing and Proofreading Services for English Documents for reviewing and editing our manuscript.

\section{References}

1. World Health Organization. Global Health Estimates 2020: Deaths by cause, age, sex, by country and by region, 2000-2019. [Update 2020; Accessed 2020 December 11]. Available from: https:/www.who.int/data/gho/data/themes/mortality-andglobal-health-estimates/ghe-leading-causes-of-death
2. Sung H, Ferlay J, Siegel RL, Laversanne M, Soerjomataram I, Jemal A, Bray F. Global cancer statistics 2020: GLOBOCAN estimates of incidence and mortality worldwide for 36 cancers in 185 countries. CA Cancer J Clin 2021; 0; 1-41.

3. Saudi Heath Council. Cancer Incidence Report, Saudi Arabia 2016. Saudi Cancer Registry. Riyadh (KSA): National Health Information Center; July 2019.

4. Anders CK, Johnson R, Litton, J, Phillips M, Bleyer A. Breast cancer before age 40 years. Semin Oncol 2009; 36: 237-249.

5. Bodmer A, Feller A, Bordoni A, Bouchardy C, Dehler S, Ess $S$, et al. Breast cancer in younger women in Switzerland 1996-2009: A longitudinal population-based study. Breast 2015; 24: 112-117.

6. Brenner DR, Brockton NT, Kotsopoulos J, Cotterchio M, Boucher BA, Kerry S, et al. Breast cancer survival among young women: a review of the role of modifiable lifestyle factors. Cancer Causes Control 2016; 27: 459-472.

7. Canadian Cancer Society's Advisory Committee on Cancer Statistics. Canadian Cancer Statistics 2015. Toronto (ON): Canadian Cancer Society; 2015.

8. Ntekim NA, Nufu FT, Campbell OB. Breast cancer in young women in Ibadan, Nigeria. Afr Health Sci 2009; 9: 242-246.

9. Shitalmala T, Rajesh SL, Kaushik D. Breast carcinoma in young females below the age of 40 years: A histopathological perspective. South Asian J Cancer 2014; 3: 97-100.

10. Foo CS, Su D, Chong CK, et al. Breast cancer in young Asian women: Study on survival. ANZ Journal of Surgery 2005; 75: 566-572.

11. Telfah, A, Obeidat M, Swailmeen A, et al. Breast Cancers in Young Women: A Retrospective Study at King Hussein Medical Center. Journal of the Royal Medical Services 2015; 22: 62-68.

12. Maggard MA, O'Connel JB, Lane KE, et al. Do young breast cancer patients have worse outcomes? J Surg Res 2003; 113: 109-113.

13. Bharat A, Aft RL, Gao F, Margenthaler JA. Patient and tumor characteristics associated with increased mortality in young women ( $\leq 40$ years) with breast cancer. J Surg Oncol 2009; 100: 248-251.

14. Cancello G, Maisonneuve P, Rotmensz N, Viale G, Mastropasqua MG, Pruneri G, et al. Prognosis and adjuvant treatment effects in selected breast cancer subtypes of very young women ( $<35$ years) with operable breast cancer. Ann Oncol 2010; 21: 1974-1981.

15. Tan P, Ellis I, Kimberly A, Edi B, Stephen F, Lakhani S, et al. The 2019 WHO classification of tumours of the breast. Histopathology 2020; 77: 181-185.

16. Goldhirsch A, Ingle JN, Gelber RD, Coates AS, Thürlimann B, Senn HJ. Thresholds for therapies: highlights of the St Gallen International Expert Consensus on the primary therapy of early breast cancer 2009. Ann Oncol 2009; 20: 1319-1329.

17. Dai X, Xiang L, Li T, Bai Z. Cancer hallmarks, biomarkers and breast cancer molecular subtypes. J Cancer 2016; 7 : 1281-1294.

18. Wang K, Ren Y, Li H, Zheng K, Jiang J, Zou T, et al. Comparison of clinicopathological features and treatments between young ( $\leq 40$ Years) and older ( $>40$ years) female breast cancer patients in west China: A retrospective, epidemiological, multicenter, case only study. PLoS One 2016; 11: e0152312. 
19. Vostakolaei FA, Broeders MM, Rostami N, van Dijck JAM, Feuth T, Kiemeney LLM, et al. Age at diagnosis and breast cancer survival in Iran. Int J Breast Cancer 2012; 2012: 517976.

20. Zeeshan S, Ali B, Ahmad K, Chagpar AB, Sattar AK. Clinicopathological features of young versus older patients with breast cancer at a single Pakistani Institution and a comparison with a National US Database. J Glob Oncol 2019; 5: 1-6.

21. Al-Shamsi HO, Alrawi S. Breast cancer screening in the United Arab Emirates: is it time to call for a screening at an earlier age? J Cancer Prev Curr Res 2018; 9: 123-126.

22. Rudat V, El-Sweilmeen H, Fadel E, Brune-Erber I, Nour AA, Bushnag Z, et al. Age of 40 years or younger is an independent risk factor for locoregional failure in early breast cancer: A single-institutional analysis in Saudi Arabia. J Oncol 2012; 2012: 370385 .

23. Nuzhat, A, Abouzaid L. Female breast cancer in different age groups: clincopathological features and treatment strategies. International Journal of Community Medicine and Public Health 2017; 4: 1399.

24. Elkum N, Dermime S, Ajarim D, Al-Zahrani A, Alsayed A, Tulbah A, et al. Being 40 or younger is an independent risk factor for relapse in operable breast cancer patients: the Saudi Arabia experience. BMC Cancer 2007; 5: 222.

25. Pathy NB, Yip CH, Taib NA, Hartman M, Saxena N, Iau P, et al. Breast cancer in a multi-ethnic Asian setting: results from the Singapore-Malaysia hospital-based breast cancer registry. Breast 2011; 20: S75-S80.

26. Kwong A, Mang OWK, Wong CHN, Chau WW, Law SCK. Breast cancer in Hong Kong, Southern China: the first population-based analysis of epidemiological characteristics, stage-specific, cancer-specific, and disease-free survival in breast cancer patients: 1997-2001. Ann Surg Oncol 2011; 18: 3072-3078.

27. Raina V, Bhutani M, Bedi R, Sharma A, Deo SV, Shukla NK, et al. Clinical features and prognostic factors of early breast cancer at a major cancer center in North India. Indian J Cancer 2005; 42: 40-45.
28. General Authority for Statistics. Demographi Survey. [Online] [Updated 2016; Accessed 2020 August 8]. Available from: https://www.stats.gov.sa/sites/default/files/en-demographicresearch-2016_2.pdf.

29. Statista. Resident population of the United States by sex and age as of July 1, 2019. [Updated 2021; Accessed 2020 October 1]. Available from: https://www.statista.com/statistics/241488/ population-of-the-us-by-sex-and-age/

30. Anders CK, Hsu DS, Broadwater G, Acharya CR, Foekens JA, Zhang Y, et al. Young age at diagnosis correlates with worse prognosis and defines a subset of breast cancers with shared patterns of gene expression. J Clin Oncol 2008; 26: 3324-3330.

31. Zhang X, Yang J, Cai H, Ye Y. Young age is an independent adverse prognostic factor in early stage breast cancer: a population based study. Cancer Manag Res 2018; 27: 4005-4018.

32. Azim HA Jr, Michiels S, Bedard PL, Singhal SK, Criscitiello C, Ignatiadis $\mathrm{M}$, et al. Elucidating prognosis and biology of breast cancer arising in young women using gene expression profiling. Clin Cancer Res 2012; 18: 1341-1351.

33. Aine M, Boyaci C, Hartman J, Häkkinen J, Mitra S, Campos $\mathrm{AB}$, et al. Molecular analyses of triple-negative breast cancer in the young and elderly. Breast Cancer Res 2021; 23: 20.

34. Ma D, Jiang YZ, Xiao Y, Xie MD, Zhao S, Jin X, Xu XE, Shao ZM. Integrated molecular profiling of young and elderly patients with triple-negative breast cancer indicates different biological bases and clinical management strategies. Cancer 2020; 126: 3209-3218.

35. Al-Thoubaity FK. Molecular classification of breast cancer: A retrospective cohort study. Ann Med Surg (Lond) 2019; 49: 44-48.

36. Radosa JC, Eaton A, Stempel M, Khander A, Liedtke C, Solomayer EF, et al. Evaluation of Local and Distant Recurrence Patterns in Patients with Triple-Negative Breast Cancer According to Age. Ann Surg Oncol 2017; 24: 698-704. 